\title{
Computer Modelling as an Aid to Forest and Woodland Restoration
}

\author{
Jonathan D. Majer ${ }^{1}$, Adam Dunn ${ }^{2}$, Jean-Paul Orsini ${ }^{3}$ \\ ${ }^{1}$ Curtin Institute for Biodiversity and Climate, Curtin University, Perth, Australia \\ ${ }^{2}$ Centre for Health Informatics, Australian Institute of Health Innovation, University of \\ New South Wales, Sydney, Australia \\ ${ }^{3}$ Orsini and Associates, Swanbourne, Australia \\ Email: J.Majer@curtin.edu.au
}

Received October $4^{\text {th }}$, 2013; revised December $7^{\text {th }}$, 2013; accepted January $3^{\text {rd }}, 2014$

\begin{abstract}
Copyright @ 2014 Jonathan D. Majer et al. This is an open access article distributed under the Creative Commons Attribution License, which permits unrestricted use, distribution, and reproduction in any medium, provided the original work is properly cited. In accordance of the Creative Commons Attribution License all Copyrights (C) 2014 are reserved for SCIRP and the owner of the intellectual property Jonathan D. Majer et al. All Copyright (c) 2014 are guarded by law and by SCIRP as a guardian.
\end{abstract}

Reclamation of terrestrial ecosystems tends to be focussed on two main land uses, mining and degraded agricultural or forested lands. Modelling has great potential to assist in both situations. The aim of many restoration programs is to restore biodiversity and a self-sustaining, fully functional ecosystem, which is intimately linked with the return of the plants, the vertebrates and, particularly, the invertebrate fauna, whose presence plays a pivotal role in most ecosystem functions and processes. A thorough understanding of these plant-fauna associations is essential if restoration is to succeed. It could also equip us with the knowledge to decide how minimalistic our information needs can be when modelling progress with restoration, for instance: by quantifying certain biophysical parameters; these plus certain vegetation indices; or by both plus a range of faunal attributes. As well as streamlining the restoration monitoring process, this could lead to the enhancement of the conservation value of the restoration, and a clear understanding of the ecological links between flora and fauna would also help develop bioindicators as components of completion criteria schedules. Using Western Australian bauxite mining in the Jarrah (Eucalyptus marginata) forest as a case study, this paper reviews rehabilitation prescriptions and trends in development of plant assemblages, invertebrate colonization and litter decomposition, and applies a systems dynamic modelling approach model to test assumptions regarding the evolution of plant-fauna assemblages in time and assess whether it is feasible to predict temporal changes in the rehabilitation of this ecosystem. Secondly, in relation to efforts to purchase and rehabilitate land to reconnect remnant woodland vegetation close to the south coast of Western Australia, network analysis and multi-level simulations are applied in order to decide the best locations to acquire land and to restore it in order to optimise connectivity.

Keywords: Jarrah Forest; Bauxite Mining; Fragmentation; Connectivity

\section{Introduction}

In Australia, where the authors are based, reclamation of disturbed lands tends to be focused on two main situations, minesite rehabilitation and restoration of degraded agricultural or forested lands. Computer simulation has great potential to assist in both situations, although it is not commonly used. The most common applications of computer simulation in reclamation involve spatial design of the area to be rehabilitated (e.g., Nicolau, 2003; Hancock, 2004), economic aspects (e.g., Bangian et al., 2011), describing plant successional patterns (e.g., Twilley et al., 1998), hydrological aspects (Sivapalan et al., 1996), or changes in forest structure (e.g., Covington et al., 2001). Few have attempted to develop or use holistic models that simultaneously take into account physical, biological and economic aspects of the process, although there are examples (e.g., Li et al., 2005). We believe that there is great potential to apply such procedures to reclamation, both in a mining and, more generally, in a degraded landscape situation. In this paper, we describe two examples where this has been investigated, one involving rehabilitated bauxite mines in the Jarrah (Eucalyptus marginata) forested area of southwestern Australia and the other concerned with the Gondwana Link initiative, which aims to reconnect fragmented woodland ecosystems in an agricultural landscape along the south coast of Western Australia.

\section{Bauxite Mine Rehabilitation}

Alcoa of Australia Ltd. (Alcoa) currently operates two bauxite mines in Western Australia and carries out an extensive rehabilitation program. Each year, approximately 600 ha of Jarrah forest (Figure 1) in southwest Western Australia are mined and then rehabilitated (Gardner \& Koch, 1991). The aim of this rehabilitation is to "maximise the forest's potential by establishing a stable, self-regenerating forest ecosystem, planned to enhance or maintain water, timber, recreation, con- 


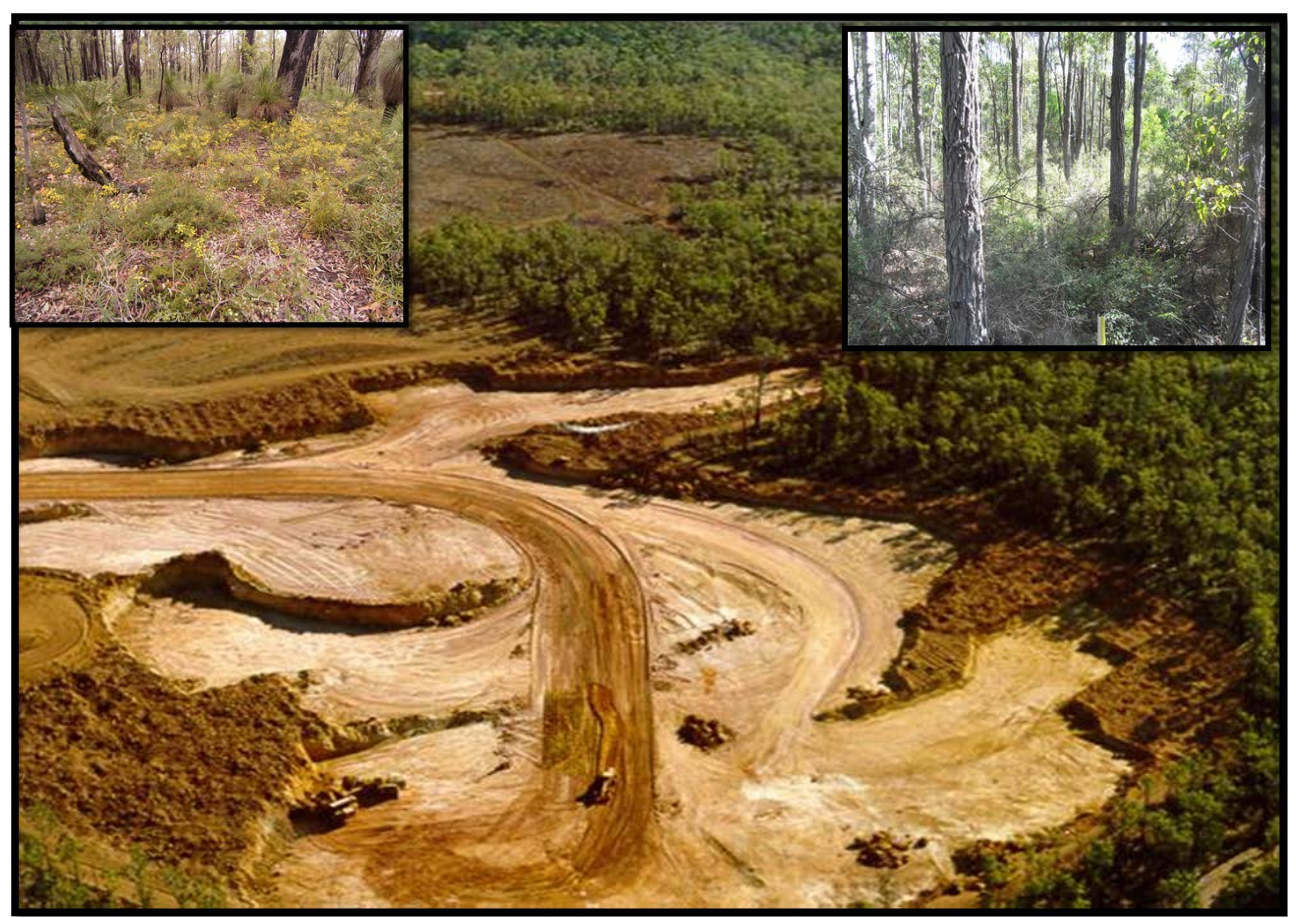

Figure 1.

Aerial view of an active bauxite mine, situated within Jarrah (Eucalyptus marginata) forest in southwest Western Australia. Left inset shows unmined jarrah forest and right inset shows 20-year-old restoration. Photos courtesy of Alcoa of Australia Ltd.

servation and/or other nominated forest values" (Nichols et al., 1991). Areas to be mined are defined and the vegetation cleared (Figure 1). The topsoil is then removed (top $150 \mathrm{~mm}$ ) and re-spread on another area to be rehabilitated. The overburden is then scraped to a depth of 200 - $800 \mathrm{~mm}$ and stockpiled for later respreading (Nichols et al., 1985). After this, the remaining caprock layer is blasted and this, plus the underlying friable material, is mined and taken away for processing. This leaves a mined pit some 2 - 5 meters lower than the surrounding forest floor (Nichols et al., 1985). After mining is completed, earthworks are carried out to reshape the pits to conform as closely as possible to the surrounding landscape. Once this has been achieved, overburden and topsoil are replaced in separate layers over the landscaped area (Koch, 2007a). The pit floor is then ripped to ameliorate the compaction that occurs as a result of the heavy machinery used in the mining process to increase water penetration, reduce erosion and facilitate root exploration (Nichols et al., 1985). The final stage of the rehabilitation program (excluding future monitoring and research) is revegetation (Figure 1).

Over the years, a number of different rehabilitation techniques have been used; in the early sites, the aim of rehabilitation was simply to establish plantations of introduced species for timber production (Gardner \& Koch, 1991). Subsequent developments in revegetation demanded the planting of native species of both tree and understorey plants (Gardner \& Koch, 1991). When the native tree species, Jarrah and Corymbia calophylla (Marri), were first introduced, seedlings were planted in rows (Nichols et al., 1985); now these trees are added as seed, along with understorey species, to give a more random distribution.

More recently, the need to carry out high-quality rehabilita- tion has become more acute, with the phasing in of performance standards and completion criteria (Mills et al., 1992; Nichols, 2006). Often, bonds are payable and these are not returned until adequate rehabilitation, which meets prescribed completion criteria, has been demonstrated (Cobby, 2006). Further to this, Mine Closure Planning was introduced into the WA Mining Act 1978 for the first time in 2010. This is a real game changer for the WA mining industry and has implications for biodiversity outcomes. The aim of mine closure planning is to ensure that, for every mine in Western Australia, a planning process is in place so the mine can be closed, decommissioned and rehabilitated to forest in an ecologically sustainable manner, consistent with agreed post-mining outcomes and land uses, and without unacceptable liability to the State (WA Department of Mines and Petroleum and WA Environmental Protection Authority, 2011).

All of this means that organisations responsible for mining and subsequent rehabilitation must be able to plan and predict future rehabilitation scenarios so that existing statutory requirements can be met. This becomes all the more demanding considering the now accepted viewpoint that restoration and maintenance of ecosystem functioning, as well as return of biodiversity, are important aspects of the rehabilitation process (Hobbs \& Cramer, 2008). Thus, in view of the complex interactions that are involved in the reclamation process, the requirement to re-establish ecosystem functioning, and the need to predict outcomes well before they are finally assessed, computer simulation has great potential to play an important role in understanding the interactions and predicting the outcomes. This paper describes a series of studies of revegetation prescriptions, subsequent invertebrate recolonization, and leaf litter decomposition in Alcoa's Western Australian bauxite mines in 
order to see how computer simulation can assist with understanding how well nutrient cycling can be re-established through appropriate rehabilitation procedures.

\section{The Gondwana Link Initiative}

Portions of the south coast of Western Australia are recognised as environmentally valuable because of high levels of biodiversity, but are at risk due to continued anthropogenic influences, particularly in the form of fragmentation and habitat loss (Figure 2). Corridors of habitat, either continuous or stepping-stone, are deemed to be valuable for the maintenance and increase of biodiversity in the region. The Gondwana Link initiative is identifying significant corridors between the woodlands of the Stirling Ranges and the Fitzgerald River National Park and is either purchasing land in this area or encouraging land owners to participate in rehabilitation schemes in order to restore the connectivity between the remaining areas of native vegetation (Bradby, 2008) (Figure 2). Acquisition of such land, and also rehabilitation measures that are needed, demands a considerable outlay of scarce financial resources. Since funds are limited for such activities, it is important to optimise the selection of areas to acquire and/or rehabilitate in order to bring about the best outcomes. Later in this paper we apply a series of spatial network analyses to quantify the connectivity between woodland fragments in order to identify a series of locations that are important to acquire for enhancing the connectivity in this region.

\section{The Alcoa Temporal Model}

\section{Background}

As outlined above, rehabilitation such as that performed by Alcoa is a complex process, with potentially varied outcomes. Dealing with the management of complex systems requires tools that allow the human mind to simplify reality in such a way as to retain the key components and relationships in the system, while discarding second-order processes. Faced with having to make complex decisions, we first need to represent reality through a "conceptual model" of essential elements and relationships which allows us to deal with complexity in an ordered and systematic fashion, which is followed by application of a numerical simulation model which allows to us quantify the response of the system to various management decisions. Such complex systems models are invaluable in their ability: to test the validity of specific assumptions; to give an estimation of the behaviour of the system and its response to various inputs by doing sensitivity analyses (running the model for a range of values of a particular parameter); and to find out what the key drivers of the system are, thus allowing managers to concentrate on the most effective management strategies.

"Stocks and Flows" models have been developed to formalise this process, using only four elements to build such conceptual models and consist of the following components:

- Stock is a Variable in the system where amounts accumulate with time, such as numbers of individuals, matter or energy. A Stock is defined by its initial value at $t=0$ and its rate of change by unit of time (called a Flow; see next point);

- Flow is the rate of change of a Stock by unit of time. This can be positive (increase) or negative (decrease) and can be a function of various Variables in the system (see next point);
- Variable (also called Converter) is any descriptive element or parameter in the system that is not a Stock or a Flow; and

- Connectors are arrows in the model showing interdependence between two elements in the model. Each connector is underpinned by a mathematical or graphical relationship which can be entered either as a numerical equation or as a two dimensional graph or series of pairs of numbers in a table.

The first challenge of the modeller is to develop a conceptual model that will be a representation of the complex system. In doing so, assumptions will need to be made, often relying on expert opinion and advice. A review of the literature will usually be needed to put together the state of knowledge on the system at the current time. Once a conceptual model has been assembled, feedback is required from key stakeholders (technical experts, scientists, industry, community members) and the conceptual model is then revised in order to take into account various inputs into the draft model and its underlying relationships.

The modeller then needs to go through two stages. The first is calibration of the model parameters by comparing the results of the model (outputs) to a set of field data. Optimisation techniques can here be used to obtain the best "fit" of the model to that data. Secondly, validation of the model is required by running the model against a separate set of field observations. This time, the parameters of the model are fixed and the validity of the model can be tested by its ability to "fit" a range of natural conditions.

In mine site rehabilitation, such as that performed by Alcoa, simulation models are an essential tool to investigate the behaviour of the environment in response to various disturbances and management strategies. To model the rehabilitation process we need data to represent the Stocks and Variables and also quantification of the flows that link these together. Fortuitously, a considerable body of research has amassed over the past 40 or so years on numerous aspects of Alcoa's rehabilitation procedures, so much so in fact that a special issue of the journal Restoration Ecology was dedicated to research carried out in relation to Alcoa (Bell \& Hobbs, 2007 and references therein). There is a problem though. Unlike the situation with modelling, say, pest-parasitoid interactions, where careful laboratory experiments enable detailed quantification of functional and numerical responses of biocontrol agents to varying pest densities (Mills \& Getz, 1996), data on relationships in minesite rehabilitation take the form of tables or graphs in papers and reports, general written descriptions of responses to different rehabilitation prescriptions, a statement of the correlations and significance values between treatments and responding variables, or simply an anecdotal understanding by experienced staff of the ways in which rehabilitation outcomes are affected by different treatments.

In situations like this, dynamic modelling packages such as STELLA $^{\circledR}$ or iThink ${ }^{\circledR}$ (from Isee Systems) or Vensim ${ }^{\circledR}$ (from Ventana Systems, Inc.) provide a user-friendly environment to develop simulation model in which all calculations are done seamlessly in the background without resorting to the use of a programming language such as Matlab or other programming code. The advantage of using simulation software such as Stella or Vensim is that the modeller can concentrate on developing and testing the model without having to spend any time on the computational aspects of the work.

Once the conceptual diagram has been developed, the rela- 


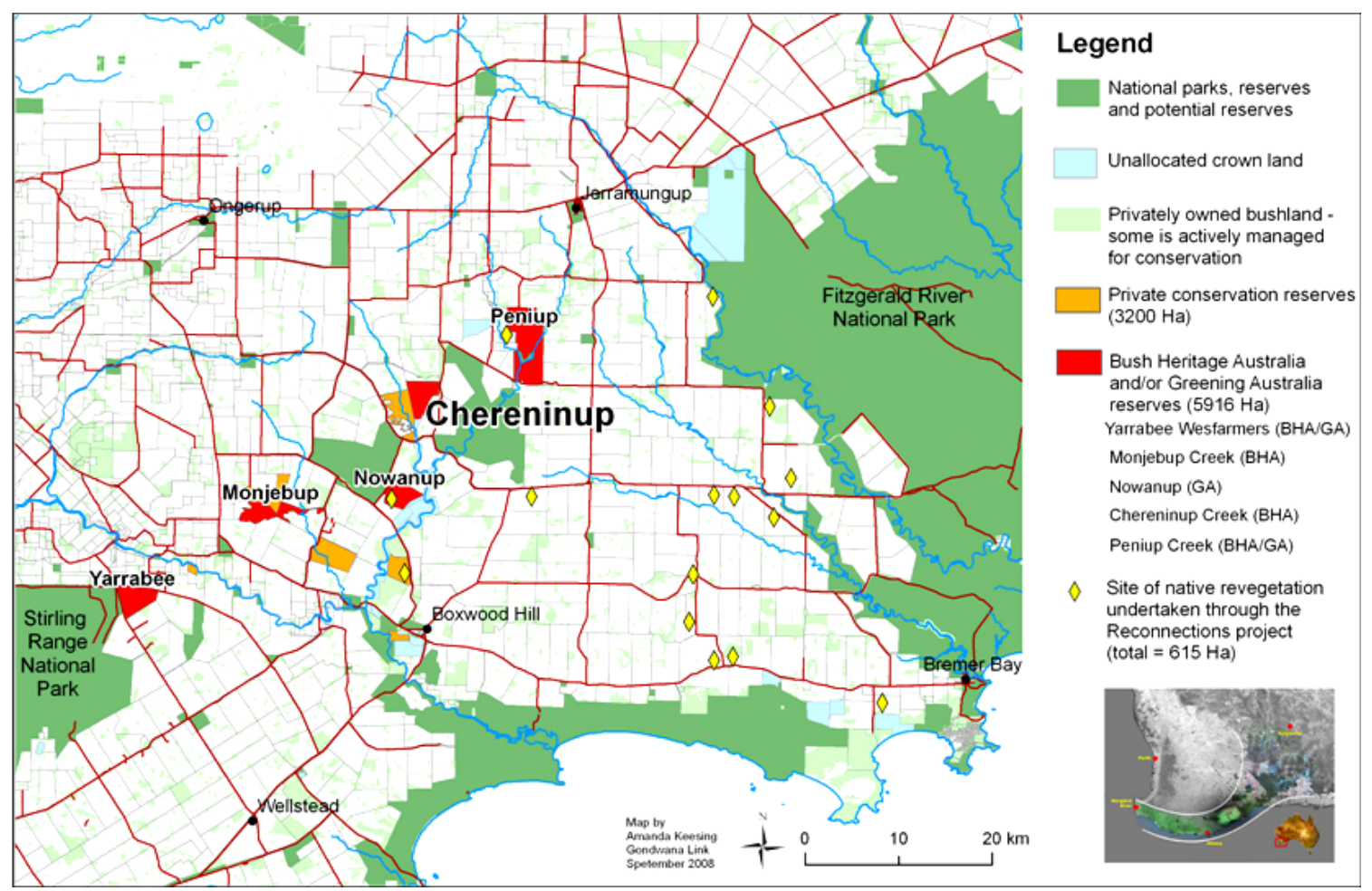

Figure 2.

Map showing how private and other conservation reserves contribute to connections between the Stirling range and Fitzgerald River National Parks. The inset shows the Gondwana Link concept. Map courtesy of Gondwana Link.

tionships between the various variables need to be entered into the software so that model testing can start straightaway, often with the end users of the model taking an active part in the process. Relationships can be entered either as a mathematical equation, a table or a graphical representation. Automated procedures can be used to fit the outputs of the model to given datasets using iterations and a predetermined metric distance between "observed" and "predicted" values. A modeller-friendly interface is available with pull-down menus, a graphic interface, with windows allowing us to enter key parameters for each run. The software has the ability to create a user-friendly interface layer with a range of tools such as explanatory notes, buttons, sliders, dials and graphs, so that end users can be guided through the running of the model and the interpretation of its outputs.

This approach to modelling provides an opportunity for clearly stating the assumptions underpinning the model. Graphical relationships behind various model assumptions can be changed in an interactive fashion by the model user, without requiring any intervention of the modeller. A model file can be compiled into a runtime version in such a way that model end users do not need to purchase the full version of the software to use the model, but only download a cheaper runtime version. However, such model users don't have access to the model development tools that allow the structure of the model to be changed, thus preventing any unauthorised model modifications. Model sharing can also be done over the internet.

\section{The Data}

One of the objectives of most rehabilitation plans, including that of Alcoa, is to create a self-sustaining forest ecosystem. An important aspect of this is the re-establishment of nutrient cycling, a process that is mediated by the interaction of micro-organisms and decomposer-associated invertebrates (Swift et al., 1979). Figure 3 provides a conceptual diagram of the links between rehabilitation prescriptions, the climatic zone in which the site is situated and, ultimately, nutrient cycling back to the soil. This is of particular importance since, despite the fact that fertilizers are applied at the time of initial revegetation, in some of Alcoa's early plots trees ceased to put on girth once the soil nutrients were exhausted (Ward \& Pickersgill, 1985). Thus, to be self-sustaining, the site needs to close the nutrient cycling process so that no further fertilizer applications are required (Grant et al., 2007).

Three of the most important inputs to the rehabilitation process are topsoil treatment, diversity of plants in the seed mix and nursery-reared plantings, and also the climatic zone in which the site is situated.

Alcoa's early revegetation efforts lacked topsoil addition, resulting in poor understorey diversity and plant cover (Koch, 2007b). This approach was soon superseded by the application of topsoil which, in early efforts, had been stored, but more recently involved topsoil freshly stripped from new areas (Koch, 2007a). Since the mid-1980's, a double-stripping technique was developed which resulted in preservation of the seed bank and nutrient reserves in the upper soil profile. All of these developments have resulted in progressive improvements in plant diversity and plant cover, the stages of which have been quantified in various publications (see papers in Bell \& Hobbs, 2007). The outcome is also influenced by the diversity of plants which are applied in the seed mix and in the planted material. Alcoa 


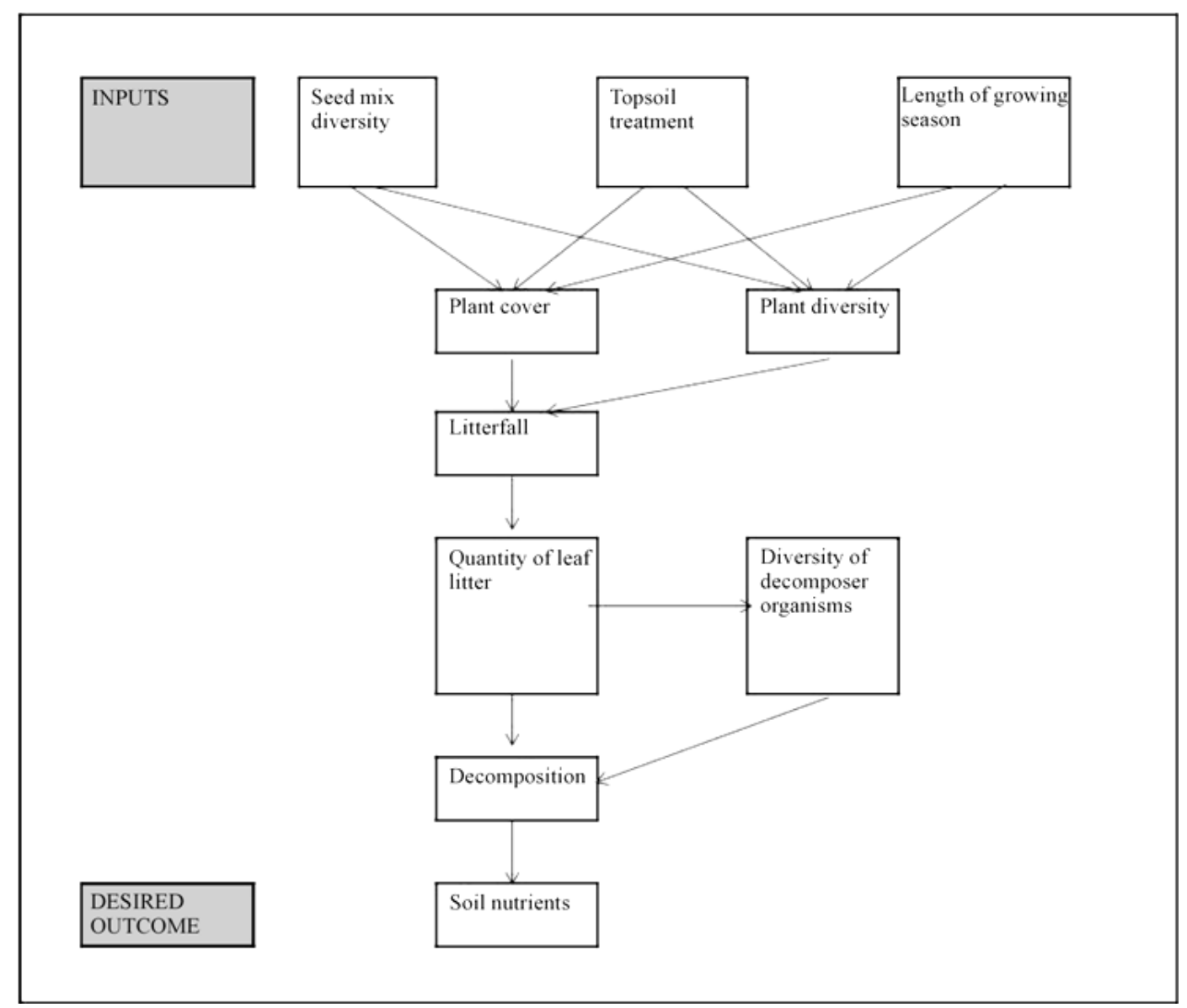

Figure 3.

Conceptual diagram of the relationships between restoration prescriptions, the climatic zone in which the site is situated, and one of the desired restoration outcomes-The re-establishment of nutrient cycling.

has invested considerable research money in devising ways to grow "recalcitrant" species, which have proved difficult to grow from seed. All of these efforts have resulted in progressive improvements in plant diversity and cover (Koch, 2007b). A third governing factor is the climatic zone in which the rehabilitated area is situated. Using ants as a responding bioindicator, Majer (1990) has observed that ecosystems become progressively more resilient as the rainfall increases, particularly if it falls during the warmer parts of the year. With exceptions, there seems to be a linear increase in ecosystem resilience with increasing rainfall. Although this has limited relevance to single minesite studies, it assists in predicting outcomes from one minesite region to another. In other words, since the relationship between rainfall (more correctly, growing season) can be quantified, it may be possible to use data from one climatic zone to another, with appropriate adjustments for prevailing climate being made to the model.

The three "inputs" in Figure 3 all influence plant cover and plant diversity in ways which have already been quantified, albeit to a limited extent. It is also known from litter-fall studies, in which collecting funnels or traps have been placed beneath vegetation of different densities and species composition, that both plant cover and diversity influence the quantity and type of litter which drops to the ground (Hatch et al., 1955). The composition of the litter is of importance, since leaves of some plants, such as nitrogen-rich acacia's, enhance the decomposition process (Swift et al., 1979; Hingston, 1980), while other species, such as eucalypts, decompose more slowly.

A large amount of data exists on the relationship between rate of litter fall and build-up of leaf litter in Jarrah forest ecosystems in which Alcoa's bauxite mines are situated. Similarly, the amount of litter has been quantified in a large range of bauxite mined areas that have been rehabilitated by a range of different methods and in ones which represent different rehabilitation ages (Majer et al., 1984). There should be no problem in combining the data from the bauxite mines with those from the surrounding forest in order to obtain a robust relationship between litter fall and standing litter biomass, with the passage of time being easy to factor in.

The relationship between litter biomass and decomposition has been quantified in a wide range of bauxite mines of differing age and rehabilitation prescription. This was achieved by placing out meshed litter bags containing known amounts of litter for 18-month periods and then measuring weight loss, litter respiration, and losses of nutrients. Strong relationships were found between these decomposition variables and the nature and age of the rehabilitation and its associated leaf litter (Ward et al., 1991).

Concurrently with the decomposition study, Greenslade and Majer (1993) sampled soil and leaf litter Collembola (spring- 
tails), a group of arthropods that is intimately tied in with the decomposition process. They found strong relationships between the diversity and abundance of springtails from the decomposition guild with the nature of the litter load. Additionally, there were similarly strong relationships between this guild of springtails and the degree of litter decomposition taking place in the various areas. There is therefore sufficient data to quantify for the model the relationships between quantity or nature of the leaf litter and the diversity of key decomposer organisms and, following on, with these and the rate of litter decomposition.

There remains one further link that is required to demonstrate how this chain of events leads on to the cycling of nutrients back to the soil, a process so necessary for a self-sustaining ecosystem. Knowing the litter load, the rate of decomposition and the amount of nutrients release per unit area (Hatch, 1955) enables this to be calculated. Additionally, Alcoa has undertaken a large amount of research into restoration of soil nutrient loads (see Grant et al., 2007), thus enabling this link in the model to be quantified.

\section{The Model}

The model (Figure 4) has three input variables. Seed mix diversity and topsoil treatment are key determinants of the rate of change in both plant cover and plant diversity. The third input variable is the climate or, more specifically, the length of growing season for the area in which the rehabilitation takes place. This variable can be altered to simulate the effects of climate change or of the region where the particular minesite is situated.

Both plant diversity and plant cover affect the rate of litter fall, which in turn relates to leaf litter. In addition, these two plant variables also influence the diversity (and abundance) of selected invertebrate groups, in this case the important decomposer organisms, the springtails. However, rate of change in springtail levels is also influenced by leaf litter, so a third connector is added to the rate of change in springtails.

At this point a negative feedback loop is added to represent the influence of litter-decomposing springtails on the rate of litter decomposition. This, in turn, influences the rate of nutrient release into the soil, which is the ultimate question that the model is designed to answer.

There are several interactions in the model where two or three connectors lead into the same flow rate descriptor. Whether these operate in an additive or synergistic manner is unknown at present, and this probably would need to be investigated during the refinement stage of the model.

\section{Conclusions}

This model is only in its initial stage. Additional interactions may need to be added in order to provide a more realistic representation of the real-life situation. Furthermore, it represents the pathway leading to the re-establishment of one ecosystem process, nutrient cycling. There are others, such as restoration of soil structure, pollination, seed dispersal, etc., all of which are equally important for the establishment of self-sustaining rehabilitation. Thus, the ultimate model will need to have a series of modules, with some of the relationships (e.g., seed mix diversity with understorey plant diversity) being shared between modules. This adds to the complexity of the task, but Alcoa's extensive research portfolio should enable a large pro- portion of the required relationships to be quantified.

Some of the relationships may lack data to enable them to be quantified for the model. In itself, knowing this is of value as it points to gaps in the research program which need to be followed up on. If time or resources do not permit this, previously quantified relationships from other mined areas, or even from other types of disturbance or other native ecosystems may be "borrowed" and incorporated into the model, possibly with adjustments being made to suit the local situation.

The majority of mining situations do not have access to the extensive research history that a large and wealthy mining company such as the one featured in this paper has. Indeed, smaller mining or resource companies could not possibly afford to undertake or fund such an extensive research program. Despite this, they still need to have an understanding of rehabilitation outcomes in order to prepare mine closure plans and/or to meet required completion criteria. One of us (JDM) has performed research on invertebrate recolonisation in minesites throughout all climatic regions of Australia, in coastal dune forest in Kwazulu, South Africa, and in both Atlantic and Amazon rain forest of Brazil (Majer, 1990; 1992; 1996; Majer \& de Kock, 1992) From these studies it is apparent that the processes involved in the resulting succession of the biota are similar, the major different being in the rate at which change occurs. It therefore seems reasonable to develop a model for one, or a few, rehabilitated areas and then adapt it to other regions or situations where a total investigation is not possible. One of the main variables that could be manipulated in the model presented here is "length of growing season".

\section{The Gondwana Link Spatial Model}

Spatial modelling of landscape patterns can be used to aid restoration by considering the effects of landscape heterogeneity on ecological function, identifying locations that benefit most from restoration efforts, and predicting the effects of natural and anthropogenic changes on the distributions of plants and animals. Landscape heterogeneity produces a range of effects on the dynamics of an ecosystem (Pickett \& Candenasso, 1995; Turner, 1989; Wiens, 1976), including both flora (With, 2002) and fauna (Lindenmayer et al., 2003). Of particular importance is the structure of edges (Haddad, 1999; Ims, 1995) and corridors, both of which have potential effects that extend beyond their immediate locations (Levin, 1992). Corridors are considered valuable components of fragmented landscapes because of the way in which they can positively contribute to the maintenance of biodiversity (Beier \& Noss, 1998).

On the south coast of Western Australia, the Gondwana Link project seeks to mitigate the risks of anthropogenic influence in the area by rehabilitating tracts of land that improve the connectivity between the woodlands of the Stirling Ranges and the Fitzgerald River National Park (Figure 2). In the context of what we are considering here, the aim of spatially explicit modelling and simulation is to determine the importance of individual corridors with regards to seed dispersal (Pearson \& Dawson, 2005) and fauna movement (McRae et al., 2008), estimating where restoration efforts are best applied, and predicting the effects of these efforts on the wider system. By identifying specific locations to target for intervention and estimating the effects of decision-making, the aim is make more efficient use of resources and avoid unintended negative consequences. Computational methods, including network analysis 

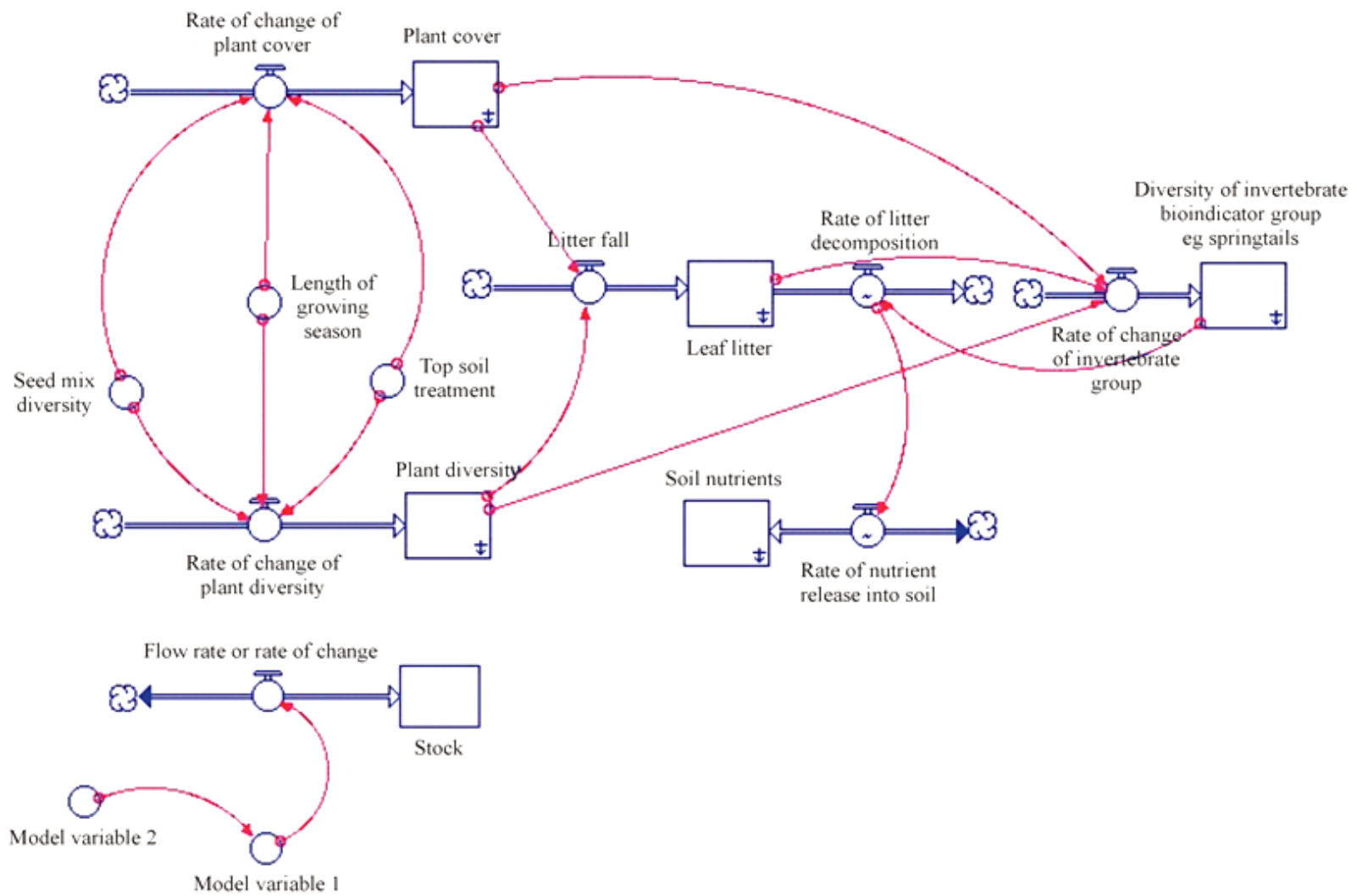

Figure 4.

Re-interpretation of the relationships shown in the conceptual diagram in Figure 3 as a systems dynamic model prepared using the STELLA ${ }^{\circledR}$ modelling package. The box beneath is a key to the symbols used in the model; "clouds" represent the outer limits of the model.

and simulation, are useful for this purpose because large-scale controlled experiments conducted on the ground are typically not feasible and traditional analytical approaches do not explicitly consider the spatial patterns of landscapes.

A major difficulty in constructing spatially-explicit models of restoration is in capturing the different ways in which organisms perceive the landscape structure (Baguette \& Van Dyck, 2007). For plants, this perception includes suitable conditions for growth, as well as the presence of vectors that perform seed dispersal (typically wind, water, animals and anthropogenic disturbance) (Jones \& Helen, 2008; Nathan \& Muller-Landau, 2000). For animals, this may also include predation, food, shelter and mating. As a consequence of these differences, a single representation of a landscape is unlikely to be appropriate for a holistic model of restoration because it will not capture the different perceptions of the organisms in the system. It is therefore important to consider a range of data sources describing the landscape to match the range of perceptions held by organisms in the system.

In what follows, we progress through an example of analysis and simulation with increasing complexity, showing how we address the problem to produce more encompassing models of ecological phenomena. As an example in network analysis, we consider how vagility and perception of habitat affect pathways of likely fauna movement (Dunn \& Majer, 2009). In simulations, we consider the example of multiple vectors of seed dispersal, which is achieved by linking multiple views of the same landscape (Dunn, 2010b; Dunn \& Majer, 2007), showing how the combined effects produce different results, similar to the way in which the "stocks and flows" approach considers feedback between elements within the system.

\section{Analysing Single-Level Landscape Patterns}

The simplest way to represent a fragmented landscape is a binary (habitat or not habitat, rather than levels of habitability) description of the landscape pattern, either as a set of habitat patches separated by a matrix (Forman, 1995), as a regular grid of pixels (for example, McRae et al., 2008; Pinto \& Keitt, 2009), or using an irregular grid (Dunn, 2010a; Holland et al., 2007) (see Figure 5). Landscape connectivity metrics use the underlying patterns of habitat in a landscape to define a network (also called a graph), in which nodes represent a patch or small area of landscape and connections between nodes represent how well-connected the nodes are in relation to movement or dispersal.

We use irregular cell-based structures to represent the landscape because they offer a higher resolution of analysis than patch-based representations and avoid the grid-induced bias associated with regular lattices (Dunn, 2010a). In irregular cell-based structures, the landscape is represented by Halton points (Halton \& Smith, 1964) and connections between nodes in the network are defined by the Delaunay triangulation (see Okabe et al., 2000).

Spatially explicit metrics (those that give values at each point on the landscape) that may be used to quantify the relative importance of locations in a landscape include the conditional minimum transit cost (Pinto \& Keitt, 2009), the circuit theory 

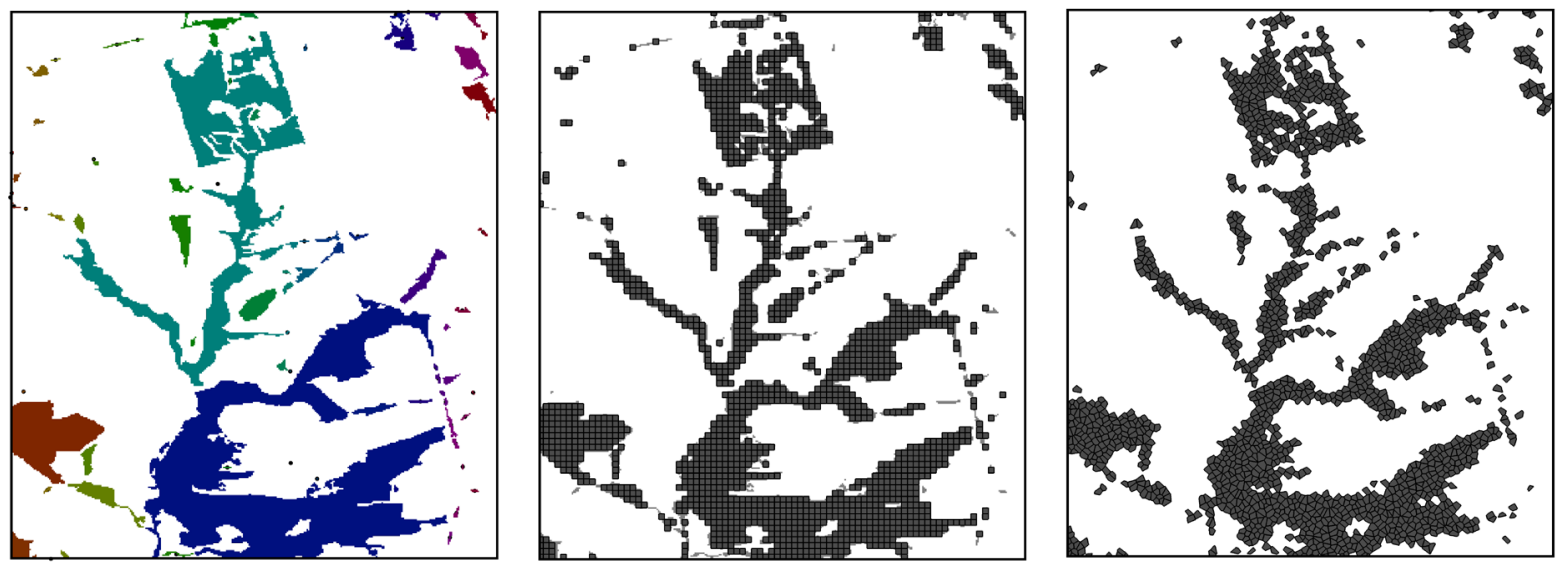

Figure 5.

Three approaches for representing habitat in a landscape are the patch (left), grid (centre) and irregular (right) decompositions applied to a small section of the Peniup-Fitzgerald corridor. The colours in the left sub-figure show 79 internally-contiguous patches (black dots indicate centroids), and in the centre and right sub-figures, discrete cells of habitat are represented by grey squares and polygons, respectively.

method (McRae et al., 2008), and the betweenness centrality methods (Figure 6). Therefore, the limitation common to the three metrics discussed above is the need to accurately quantify habitat perception (what values are associated with different habitat and non-habitat areas) and vagility (specifically, over what distances should nodes spanning non-habitat be considered connected) for the organisms in question (Johnson et al., 1992; Wiens, 1976). Validating the accuracy of habitat perception and vagility or dispersal estimates is rarely performed when applying spatially-explicit models and should be incurporated into future applications.

In applying these methods to restoration, there are two aims. One is to identify and strengthen pathways that are already important in organism movement, which may be done by widening bottlenecks or targeted improvement of quality. The other is to examine how selective restoration can create new pathways, including redundant pathways engineered to reduce the reliance on others. Therefore, from a practical perspective, the approach to restoration using these analyses may involve either: 1) identifying important locations to improve, maintain or monitor; or 2) making changes to the landscape pattern in simulations to examine what the likely effects on connectivity may be if those changes were applied on the ground.

\section{Simulating Single-Vector Dispersal}

In the above examples using network analysis, each cell or patch is considered to be a static representation of what is contained within a small area of landscape and their spatial arrangement defines their importance with respect to providing connectivity. When simulating the behaviour of organisms over a landscape, we are considering changes that happen over time. This is achieved by attaching information to each of the cells that collectively represent the landscape, and creating the rules that allow those states to change over time, in response to external stimuli or the state changes of other cells. In this case, the rules are implemented to model propagation.

In this case, we use the same irregular cell representation as in the network analysis above, and allow each cell to hold a value between zero and one, where zero represents the absence of a population of a hypothetical organism, and one represents the presence of that organism. We make the assumption that dispersal may occur through cells representing the matrix, albeit with a much lower likelihood than through habitat cells. This assumption is consistent with studies examining the quailty of the matrix for dispersal of organisms (Fahrig, 2001; Murphy \& Lovett-Doust, 2004).

In the previous section, we found that the Peniup-Fitz corridor features several important stepping-stone pathways that separate the Fitzgerald River biosphere from Peniup (as well as further west to the Stirling Ranges). We also concluded that stepping-stone pathways may be problematic for some species without the ability to travel easily through non-habitat areas. By simulating dispersal from a single location in the Peniup region, it is possible to watch the spread of a particular species (or indeed a specific genotype, disease, or invasive species) based on the relative ease of dispersal through habitat and non-habitat regions. By repeating the simulations many times, it is possible to estimate the likelihood of finding a species in a specific location after a specified amount of time.

In the beginning of each simulation, one cell is assigned a positive state value (i.e. it contains a population of the hypothetical plant species), and the rest are set with a zero state value, representing a single population in one location. Simulations progress by applying neighbourhood-based rules to each cell-where inactive cells become active as a consequence of having active cells within their neighbourhood. Simulations of propagation are common across a range of disciplines and there are several ways to construct the rules for updating the state of individual cells in a landscape over time. Probabilistic updating is performed by assigning a probability to each connection, which most closely resembles the probabilistic rules used in cellular automata applications (see Chopard \& Droz, 1998; Schönfisch, 1997). Other non-deterministic approaches to modelling movement over landscapes include approximations and modifications to random walks or Levy flights (see Benhamou, 2007). The results of the simulation show the burst-like spread of the population-as the less likely dispersal through the matrix reaches each new patch, the propagation within that patch proceeds quickly (Figure 7).

Seed dispersal curves offer a method for calibrating spatially explicit simulations. Seed dispersal curves are used for modelling seed dispersal but are rarely used in combination with spa- 

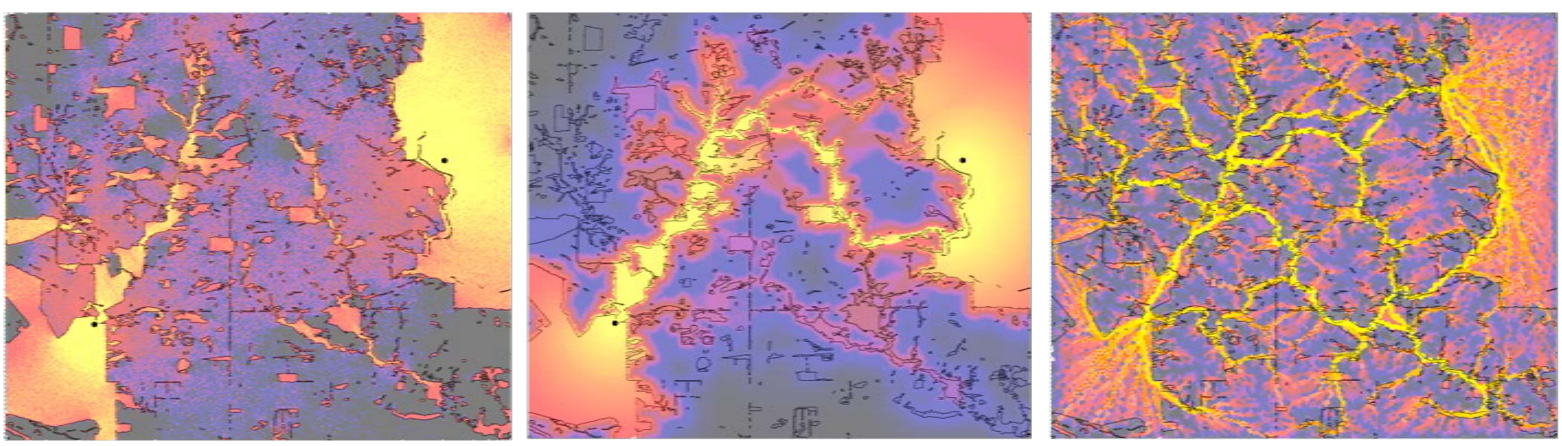

Figure 6.

The results of analyses using the circuit theory (left), conditional minimum transit cost (centre) and betweenness centrality (right) approaches on the Peniup-Fitzgerald corridor (considering only vegetation as habitat) reveals differences between the methods. Each analysis uses an identical irregular structure and connectivity, and edges through habitat cells are considered 100 times less costly than edges attached to non-habitat cells. Points are labelled (black circles) where they are required by the algorithm (see text).
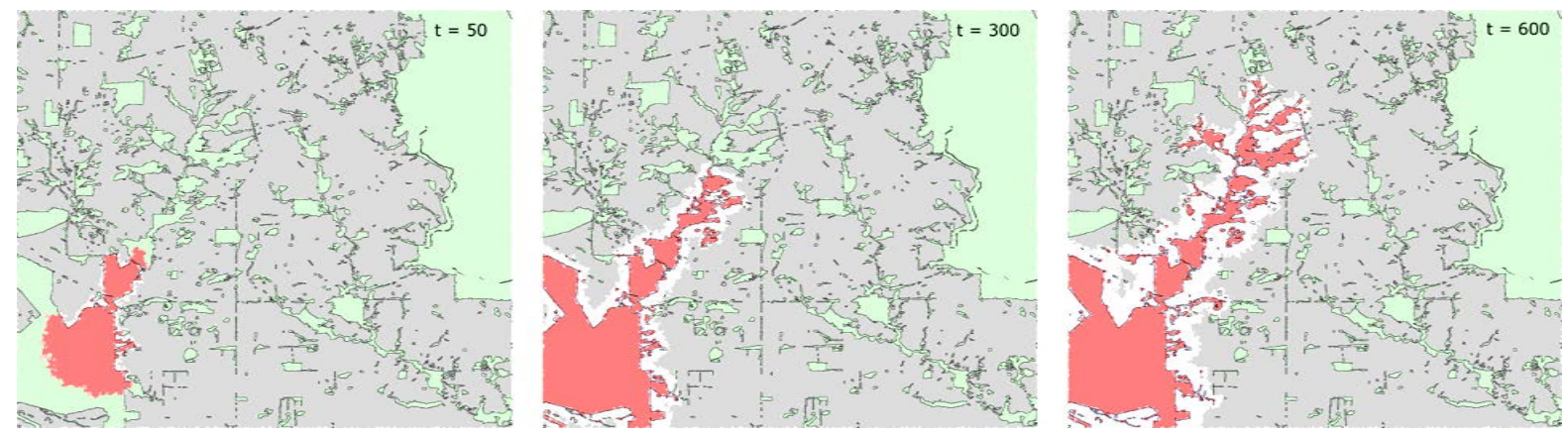

Figure 7.

In a single-layer simulation of seed dispersal by fauna, spread is illustrated through areas amenable to growth (red) and across non-habitat (white to blue) at three time steps. In this hypothetical example, areas with vegetation are 100 times more likely to produce seed dispersal, creating burst-like population growth as new vegetation patches are encountered.

tially explicit models (Jones \& Helen, 2008; Nathan \& MullerLandau, 2000). Seed dispersal curves can be used to calibrate because it is possible to train the parameters of the simulation to produce the same rate of spread in habitat and across nonhabitat areas using dispersal curves derived empirically in a variety of habitat patterns. From a practical perspective, the method for calibrating the seed dispersal curve to the simulation relies on taking the empirical information about seed dispersal in different environments (different proportions of habitat and matrix, and different levels of fragmentation) and calibrating that against the rates of spread in simulations.

\section{Using Multiple-Layer Extensions to Compose Data Sources and Phenomena}

To achieve a more holistic model of ecosystem functions and the restoration efforts designed to promote them, it is important to consider interactions. Concepts from hierarchical patch dynamics (Wu, 1995) may be implemented using a hierarchical extension of the cell-based simulation method described above (Dunn, 2010b; Dunn \& Majer, 2007). The aim is to provide the framework for connecting multiple layers of landscape information "vertically" allowing interaction of different behaviours (in this case, seed dispersal by different vectors) with different types of information at each level.

In an extended version of the simulations described above, the landscape is represented by two layers instead of one. The first layer remains as the vegetation and the second layer is an estimate of anthropogenic disturbance from the locations of roads and towns. Since the model represents two forms of dispersal, there are separate rules that govern the updating of cell states in each layer. In the vegetation layer, the rules are used to model the dispersal of seeds by frugivores. In the anthropogenic disturbance layer, the rules estimate the effect of anthropogenic disturbance on the spread of the hypothetical plant species. At each time step, the rules are applied for each layer, and the two layers are combined to produce a single estimate of the spatial distribution of the plant at each time step. The result is a model of the combined effects of the two forms of dispersal (Figure 8).

In Figure 8, the distance covered by seed dispersal has increased dramatically from the spread seen in the single-layer example. The seed dispersal has easily reached the Fitzgerald River biosphere. In the case of an invasive species, the increased spread due to human movement along the roadways is undesirable. The simulations provide targets for which to enact policy (in particular, along Maringarup Road in the south, and Carlawillup Road in the north), to reduce the effects of anthropogenic disturbance and mitigate unwanted spread.

While the examples above rely on simple state information to represent the presence or absence of a population of plants, the process of modelling may require more detailed state information such as seasonal and climate effects, and the more detailed kinds of feedback captured in system dynamics models of an ecological system (see above). However, as with most modelling (Epstein, 2008), the aim is to produce the simplest model that replicates and predicts the behaviour of the system, pro- 

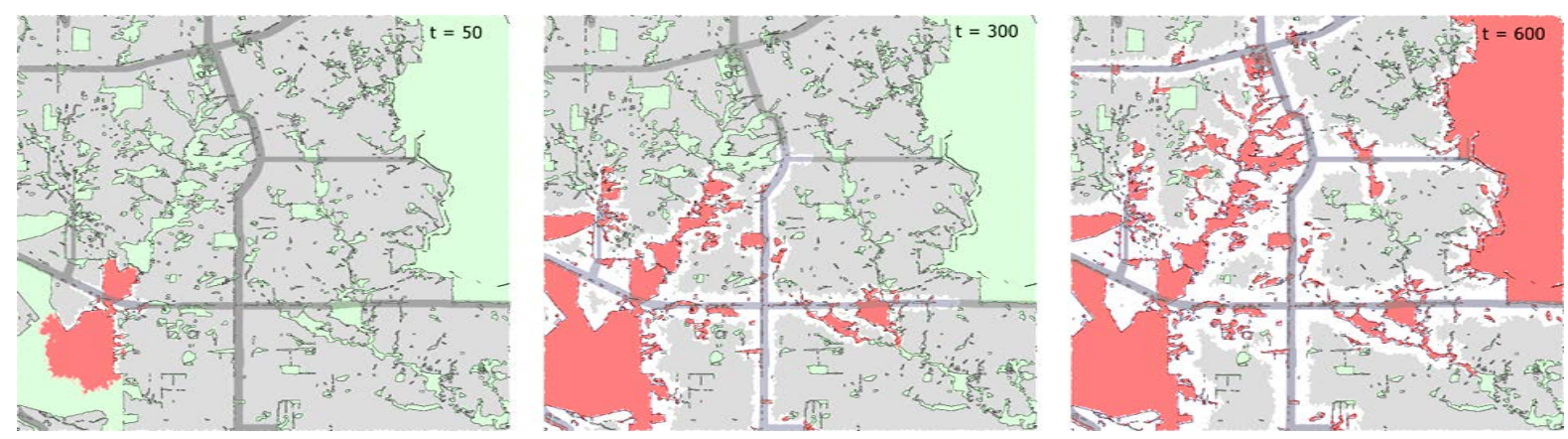

Figure 8.

Intermediate steps in a simulation of single-origin dispersal using two levels of information and two forms of dispersal. The two layers include a vegetation layer (green) and an estimate of anthropogenic disturbance along roads (dark grey), which are superimposed to produce a single image. The spread is illustrated through locations amenable to growth (red) and as dispersal across non-habitat (white to blue) at three points in the simulation.

viding decision support for restoration efforts to increase efficiency and avoid unintended consequences.

\section{Conclusion}

The two case studies provided in this paper serve to illustrate the potential for computer modelling and simulation to contribute to the design and implementation of restoration following any type of land use, be it mining, forestry, agriculture or whatever. The challenges in obtaining the required data are great, although in one regard, they assist those concerned with restoration to target their research to where it is most needed. We believe that these procedures offer great potential to enhance the quality of restoration and to enable it to be carried out in the most effective and economical manner.

\section{REFERENCES}

Baguette, M., \& Van Dyck, H. (2007). Landscape connectivity and animal behavior: Functional grain as a key determinant for dispersal. Landscape Ecology, 22, 1117-1129.

http://dx.doi.org/10.1007/s10980-007-9108-4

Bangian, A. H., Ataei, M., Sayadi, A., \& Gholinejad, A. (2011). Fuzzy analytical hierarchy processing to define optimum post mining land use for pit area to clarify reclamation costs. Gospodarka Surowcami Mineralnymi, 27, 145-168.

Beier, P., \& Noss, R. F. (1998). Do habitat corridors provide connectivity? Conservation Biology, 12, 1241-1252.

http://dx.doi.org/10.1046/j.1523-1739.1998.98036.x

Bell, D. T., \& Hobbs, R. J. (2007). Jarrah forest ecosystem restoration: A foreword. Restoration Ecology, 15, S1-S2.

Benhamou, S. (2007). How many animals really do the Levy walk? Ecology, 88, 1962-1969. http://dx.doi.org/10.1890/06-1769.1

Bodin, Ö., \& Norberg, J. (2007). A network approach for analyzing spatially structured populations in fragmented landscapes. Landscape Ecology, 22, 31-44. http://dx.doi.org/10.1007/s10980-006-9015-0

Bodin, Ö., \& Saura, S. (2010). Ranking individual habitat patches as connectivity providers: Integrating network analysis and patch removal experiments. Ecological Modelling, 221, 2393-2405.

http://dx.doi.org/10.1016/j.ecolmodel.2010.06.017

Borgatti, S. P., Mehra, A., Brass, D. J., \& Labianca, G. (2009). Network analysis in the social sciences. Science, 323, 892-895. http://dx.doi.org/10.1126/science.1165821

Bradby, K. (2008). Gondwana Link: A Landscape Scale Restoration Project in South-West WA. Global Restoration Network Report, Top 25 Ecological Restoration Projects in Australasia.

http://www.gondwanalink.org/GLink GRNreport.pdf

Chopard, B., \& Droz, M. (1998). Cellular automata modeling of phy- sical systems. Cambridge: Cambridge University Press. http://dx.doi.org/10.1017/CBO9780511549755

Cobby, G. (2006). Review of environmental performance bonds in Western Australia. In A. Fourie, \& M. Tibbett (Eds.), Mine closure 2006 (pp. 75-80). Perth: Australian Centre for Geomechanics.

Covington, W. W., Fulé, P. Z., Hart, S. C., \& Weaver, R. P. (2001). Modeling ecological restoration effects on Ponderosa pine forest structure. Restoration Ecology, 9, 421-431. http://dx.doi.org/10.1046/j.1526-100X.2001.94011.x

Dunn, A. G., \& Majer J. D. (2007). In response to the continuum model for fauna research: A hierarchical, patch-based model of spatial landscape patterns. Oikos, 116, 1413-1418.

http://dx.doi.org/10.1111/j.0030-1299.2007.15931.x

Dunn, A. G., \& Majer, J. D. (2009). Measuring connectivity patterns in a macro-corridor on the south coast of Western Australia. Ecological Management \& Restoration, 10, 51-57.

Dunn, A. G. (2010a). Grid-induced biases in connectivity metric implementations that use regular grids. Ecography, 33, 627-631.

Dunn, A. G. (2010b). Hierarchical cellular automata methods. In: A. G. Hoekstra, J. Kroc, \& P. M. A. Sloot (Eds.), Simulating complex systems by cellular automata (pp. 59-80). Berlin and Heidelberg: Springer-Verlag. http://dx.doi.org/10.1007/978-3-642-12203-3_4

Epstein, J. M. (2008). Why model? Journal of Artificial Societies and Social Simulation, 11, 12.

Fahrig, L. (2001). How much habitat is enough? Biological Conservation, 100, 65-74. http://dx.doi.org/10.1016/S0006-3207(00)00208-1

Forman, R. T. T. (1995). Some general principles of landscape and regional ecology. Landscape Ecology, 10, 133-142. http://dx.doi.org/10.1007/BF00133027

Freeman, L. C. (1977). A set of measures of centrality based on betweenness. Sociometry, 40, 35-41. http://dx.doi.org/10.2307/3033543

Gardner, J. H., \& Koch, J. M. (1991). Re-establishing the jarrah forest flora on rehabilitated bauxite mines in the Darling Range, Western Australia. Proceedings of the Protective Custody-Plant Conservation Conference. Canberra: Australian National Botanic Gardens and Australian National Parks and Wildlife Service.

Grant, C. D., Ward, S. C., \& Morley, S. C. (2007). Return of ecosystem function to restored bauxite mines in Western Australia. Restoration Ecology, 15, S94-S103.

http://dx.doi.org/10.1111/j.1526-100X.2007.00297.x

Greenslade, P., \& Majer, J. D. (1993). Recolonisation by collembola of rehabilitated bauxite mines in Western Australia. Australian Journal of Ecology, 18, 385-394. http://dx.doi.org/10.1111/j.1442-9993.1993.tb00466.x

Haddad, N. M. (1999). Corridor use predicted from behaviours at habitat boundaries. The American Naturalist, 153, 215-227. http://dx.doi.org/10.1086/303163

Halton, J. H., \& Smith, G. B. (1964). Radical-inverse quasi-random point sequence. Communications of the ACM, 7, 701-702. http://dx.doi.org/10.1145/355588.365104 
Hancock, G. R. (2004). The use of landscape evolution models in mining rehabilitation design. Environmental Geology, 46, 561-573. http://dx.doi.org/10.1007/s00254-004-1030-3

Hatch, A. B. (1955). The influence of plant litter on the jarrah forest soils of the Dwellingup region. Western Australia. Leaflet No. 70. Perth: Commonwealth of Australia, Forest and Timber Bureau.

Hingston, F. J. (1980). Nitrogen in litter and soils with reference to the jarrah forest ecosystem. In R. A. Rummery, \& F. J. Hingston (Eds.), Managing the nitrogen economies of natural and man-made forest ecosystems (pp. 229-249). Perth: CSIRO.

Hobbs, R. J., \& Cramer, V. A. (2008). Restoration ecology: Interventionist approaches for restoring and maintaining ecosystem function in the face of rapid environmental change. Annual Review of Environment and Resources, 33, 39-61.

http://dx.doi.org/10.1146/annurev.environ.33.020107.113631

Holland, E. P., Aegerter, J. N., Dytham, C., \& Smith, G. C. (2007). Landscape as a model: The importance of geometry. PLoS Computational Biology, 3, e200. http://dx.doi.org/10.1371/journal.pcbi.0030200

Ims, R. A. (1995). Movement patterns related to spatial structures. In A. Hansson, L. Fahrig, \& G. Merriam (Eds.), Mosaic landscapes and ecological processes (pp. 85-109). London: Chapman \& Hall. http://dx.doi.org/10.1007/978-94-011-0717-4_4

Johnson, A., Wiens, J., Milne, B., \& Crist, T. (1992). Animal movements and population dynamics in heterogeneous landscapes. Landscape Ecology, 7, 63-75. http://dx.doi.org/10.1007/BF02573958

Jones, F. A., \& Helen, C. M.-L. (2008). Measuring long-distance seed dispersal in complex natural environments: An evaluation and integration of classical and genetic methods. Journal of Ecology, 96, 642-652. http://dx.doi.org/10.1111/j.1365-2745.2008.01400.x

Koch, J. M. (2007a). Alcoa's mining and restoration process in South Western Australia. Restoration Ecology, 15, S11-S16. http://dx.doi.org/10.1111/j.1526-100X.2007.00288.x

Koch, J. M. (2007b). Restoring a jarrah forest understorey vegetation after bauxite mining in Western Australia. Restoration Ecology, 15, S26-S39. http://dx.doi.org/10.1111/j.1526-100X.2007.00290.x

Levin, S. A. (1992). The problem of pattern and scale in ecology: The Robert H. MacArthur Award lecture. Ecology, 73, 1943-1967. http://dx.doi.org/10.2307/1941447

Li, D., Wang, Y., \& Fu, Z. (2005). An intelligent decision support system for revegetation and reclamation of land contaminated from coal mine wastes. Gospodarka Surowcami Mineralnymi, 21, 41-55.

Lindenmayer, D. B., McIntyre, S., \& Fischer, J. (2003). Birds in eucalypt and pine forests: Landscape alteration and its implications for research models of faunal habitat use. Biological Conservation, 110, 45-53. http://dx.doi.org/10.1016/S0006-3207(02)00174-X

Majer, J. D., \& de Kock, A. E. (1992). Antrecolonisation of sand mines near Richards Bay, South Africa-An evaluation of progress with rehabilitation. South African Journal of Science, 88, 31-36.

Majer, J. D. (1990). Rehabilitation of disturbed lands: Long-term prospects for the recolonisation of fauna. In: D. Saunders, R. How, \& A. Hopkins (Eds.), Australian ecosystems: 200 years of utilisation, degradation and reconstruction (pp. 509-519). Melbourne: Blackwell.

Majer, J. D. (1992). Ant recolonisation of rehabilitated bauxite mines of Poços de Caldas, Brasil. Journal of Tropical Ecology, 8, 97-108. http://dx.doi.org/10.1017/S0266467400006155

Majer, J. D. (1996). Ant recolonization of rehabilitated bauxite mines at Trombetas, Pará, Brazil. Journal of Tropical Ecology, 12, 257-273. http://dx.doi.org/10.1017/S0266467400009445

Majer, J. D., Day, J. E., Kabay, E. D., \& Perriman, W. S. (1984). Recolonisation by ants in bauxite mines rehabilitated by a number of different methods. Journal of Applied Ecology, 21, 355-375. http://dx.doi.org/10.2307/2403059

McRae, B. H., Dickson, B. G., Keitt, T. H., \& Shah, V. B. (2008). Using circuit theory to model connectivity in ecology, evolution, and conservation. Ecology, 89, 2712-2724. http://dx.doi.org/10.1890/07-1861.1

Mills, C., Chandler, R., \& Caporn, N. (1992). Completion criteria. Proceedings of Conference on Management and Rehabilitation of Mined Lands. Perth: Curtin University of Technology.
Mills, N. J., \& Getz, W. M. (1996). Modelling the biological control of insect pests: A review of host-parasitoid models. Ecological Modelling, 92, 212-143. http://dx.doi.org/10.1016/0304-3800(95)00177-8

Murphy, H. T., \& Lovett-Doust, J. (2004). Context and connectivity in plant metapopulations and landscape mosaics: Does the matrix matter? Oikos, 105, 3-14. http://dx.doi.org/10.1111/j.0030-1299.2004.12754.x

Nathan, R., \& Muller-Landau, H. C. (2000). Spatial patterns of seed dispersal, their determinants and consequences for recruitment. Trends in Ecology \& Evolution, 15, 278-285.

http://dx.doi.org/10.1016/S0169-5347(00)01874-7

Nichols, O. G. (2006). Developing completion criteria for native ecosystem reconstruction-A challenge for the mining industry. In A. Fourie, \& M. Tibbett (Eds.), Mine closure 2006 (pp. 61-74). Perth: Australian Centre for Geomechanics.

Nichols, O. G., Carbon, B. A., Colquhoun, I. J., Croton, J. T., \& Murray, N. N. J. (1985). Rehabilitation after bauxite mining in south-western Australia. Landscape Planning, 12, 75-92. http://dx.doi.org/10.1016/0304-3924(85)90071-1

Nichols, O. G., Koch, J. M., Taylor, S., \& Gardner, J. (1991). Conserving biodiversity. Proceedings of the Australian Mining Industry Council Environmental Workshop (pp.116-136). Perth: Australian Mining Industry Council.

Nicolau, J.-M. (2003). Trends in relief design and construction in opencast mining reclamation. Land Degradation \& Development, 14, 215-226. http://dx.doi.org/10.1002/ldr.548

Okabe, A., Boots, B., Sugihara, K., \& Chui, S. N. (2000). Spatial tessellations-Concepts and applications of Voronoi diagrams. Chichester: Wiley. http://dx.doi.org/10.1002/9780470317013

Pearson, R. G., \& Dawson, T. P. (2005). Long-distance plant dispersal and habitat fragmentation: Identifying conservation targets for spatial landscape planning under climate change. Biological Conservation, 123, 389-401. http://dx.doi.org/10.1016/j.biocon.2004.12.006

Pickett, S. T. A., \& Candenasso, M. L. (1995). Landscape ecology: Spatial heterogeneity in ecological systems. Science, 269, 331-334. http://dx.doi.org/10.1126/science.269.5222.331

Pinto, N., \& Keitt, T. (2009). Beyond the least-cost path: Evaluating corridor redundancy using a graph-theoretic approach. Landscape Ecology, 24, 253-266. http://dx.doi.org/10.1007/s10980-008-9303-y

Schönfisch, B. (1997). Anisotropy in cellular automata. Biosystems, 41, 29-41. http://dx.doi.org/10.1016/S0303-2647(96)01664-4

Sivapalan, M., Ruprecht, J. K., \& Viney, N. R. (1996). Water and salt balance modelling to predict the effects of land-use changes in forested catchments. 1. Small catchment water balance model. Hydrological Processes, 10, 393-411.

http://dx.doi.org/10.1002/(SICI)1099-1085(199603)10:3<393::AIDHYP307>3.0.CO;2-\#

Swift, M. J., Heal, O. W., \& Anderson, J. M. (1979). Decomposition in terrestrial ecosystems. Oxford: Blackwell.

Turner, M. G. (1989). Landscape ecology: The effect of pattern on process. Annual Review of Ecological Systems, 20, 171-197. http://dx.doi.org/10.1146/annurev.es.20.110189.001131

Twilley, R. R., Rivera-Monroy, V. H., Chen, R., \& Botero, L. (1998). Adapting an ecological mangrove model to simulate trajectories in restoration ecology. Marine Pollution Bulletin, 37, 404-419. http://dx.doi.org/10.1016/S0025-326X(99)00137-X

WA Department of Mines and Petroleum and WA Environmental Protection Authority (2011). Guidelines for Preparing Mine Closure Plans (78 p). Perth: Government of Western Australia.

Ward, S. C., \&. Pickersgill, G. E. (1985). Nutrient distribution in two eucalypt plantations growing on rehabilitated bauxite mines. Australian Journal of Ecology, 10, 111-124. http://dx.doi.org/10.1111/j.1442-9993.1985.tb00873.x

Ward, S. C., Majer, J. D., \& O’Connell, A. M. (1991). Decomposition of eucalypt litter on rehabilitated bauxite mines. Australian Journal of Ecology, 16, 251-257. http://dx.doi.org/10.1111/j.1442-9993.1991.tb01051.x

Wiens, J. A. (1976). Population responses to patchy environments. Annual review of Ecology and Systematics, 7, 81-120. http://dx.doi.org/10.1146/annurev.es.07.110176.000501 
With, K. (2002). The landscape ecology of invasive spread. Conservation Biology, 16, 1192-1203.

http://dx.doi.org/10.1046/j.1523-1739.2002.01064.x
Wu, J. (1995). From balance-of-nature to hierarchical patch dynamics: A paradigm shift in ecology. The Quarterly Review of Biology, 70, 439-466. http://dx.doi.org/10.1086/419172 